\title{
POTENSI TUMBUHAN OBAT DI DESA BEMBAN KAWASAN HUTAN LINDUNG GUNUNG AMBAWANG KECAMATAN KUBU KABUPATEN KUBU RAYA
}

\author{
(Potential of medicinal plants in Bemban Village in the protected forest area of Gunung \\ Ambawang of Kubu Subdistrict, Kubu Raya Regency)
}

\author{
Yuli Rianti, Purwati, Wahdina \\ Fakultas Kehutanan Universitas Tanjungpura Pontianak, Jl. Daya Nasional Pontianak 78124 \\ Email : yulirianti89@gmail.com
}

\begin{abstract}
The potential of forest products is not only in the form of timber, but also other valuable benefits that can contribute to human life such as medicinal plants for health. Medicinal plants are plants that have functions and nourishments as medicine and used for therapy or prevention of various diseases. The term "medicinal" itself means " to contain certain active substances that can treat certain diseases and contain certain active substances, contain a resultant effect or synergy of various substances which have the healing effects. This research aims to assess the potential and utilization of medicinal plants and herbs found in Bemban Village in the Protected Forest Area of Gunung Ambawang of Kubu Subdistrict, Kubu Raya Regency. The research was carried out in Bemban Village in the Protected Forest Area of Gunung Ambawang of Kubu Subdistrict, Kubu Raya Regency for more or less 4 weeks effective in the field. The vegetation analysis method in the field of the research was carried out with plot line method placed by purposive sampling. The research sites had 3 observation lines with a plot length of 100-300 m, the number of observation plots was 12 plots and each plot area was 0,04 ha with distance between the plots in one line was $50 \mathrm{~m}$. So, the total area of observation was $0,04 \mathrm{ha}$. The results showed that there were 87 medicinal plant species of 59 families. A total of 58 medicinal plant species of 34 families were taken directly by the community around the yard, and 29 species of medicinal plants of 25 families found from the analysis of the vegetation in the field.
\end{abstract}

Keywords: Bemban Village, Gunung Ambawang, Medicinal Plants

\section{PENDAHULUAN}

Ilmu kehutanan tidak lepas dari mengenal berbagai jenis pohon yang menjadi penyusunnya baik itu hasil hutan kayu maupun hasil hutan bukan kayu. Potensi hasil hutan tidak hanya berupa kayu, tetapi juga manfaat lain yang tak ternilai yang dapat memberikan kontribusi terhadap kehidupan manusia seperti tumbuhan hutan berkhasiat obat (THBO) untuk kesehatan. Tumbuhan obat merupakan jenis-jenis tumbuhan yang memiliki fungsi dan khasiat sebagai obat dan dipergunakan untuk penyembuhan maupun mencegah berbagai penyakit, khasiat obat sendiri mempunyai arti mengandung zat aktif yang bisa mengobati penyakit tertentu atau memiliki kandungan zat aktif tertentu tetapi memiliki kandungan efek resultan atau sinergi dari berbagai zat yang mempunyai efek mengobati.

Jaminan akan ketersediaan obat yang aman bagi penggunanya, berkhasiat, tidak 
ada efek samping dan dengan harga yang terjangkau dianggap perlu pada masa kini. Masyarakat di daerah pedesaan masih banyak menggunakan obat-obatan yang berasal dari tumbuh-tumbuhan atau pengobatan yang dilakukan secara tradisional, karena disamping murah, tidak ada efek samping dibanding dengan menggunakan obat-obat modern atau obatobat dari bahan kimia, dan sebagian dari tumbuhan obat tersebut juga mudah didapat di sekitar pekarangan rumah. Masyarakat biasanya memanfaatkan bagian tumbuhan yang terdiri dari umbi, akar, batang, bunga, dan buah sebagai obat tradisional. Penggunaan tumbuhan obat sebagai obat bisa dengan cara diminum, ditempel, sehingga kegunaannya dapat memenuhi konsep kerja reseptor sel dalam menerima senyawa kimia atau rangsangan (Winarto, 2007).

Masyarakat sekitar kawasan hutan memanfaatkan tumbuhan obat yang ada sebagai bahan baku obat berdasarkan pengetahuan tentang pemanfaatan tumbuhan obat yang diwariskan secara turun-temurun. Keahlian pengobatan tradisional masyarakat umumnya dikuasai oleh orang-orang tertentu yang diyakini memiliki pengetahuan ilmu tentang obatobatan. Penelitian ini bertujuan untuk mengetahui potensi dan jenis tumbuhan obat serta pemanfaatan tumbuhan obat yang terdapat di Desa Bemban Kawasan Hutan Lindung Gunung Ambawang Kecamatan Kubu Kabupaten Kubu Raya.

\section{METODE PENELITIAN}

Penelitian dilakukan mulai tanggal 2 Maret sampai 30 Maret 2013 di Desa Bemban Kawasan Hutan Lindung Gunung
Ambawang Kecamatan Kubu, Kabupaten Kubu Raya. Metode penelitian menggunakan metode survey melalui wawancara mendalam (indept survey) terhadap responden yang dipilih secara purposive sampling, diantaranya : kepala desa, kepala adat, ketua masyarakat, dukun kampung dan masyarakat lainnya. Wawancara dilakukan untuk memperoleh info jenis tumbuhan obat yang digunakan masyarakat setempat (responden) secara langsung.

Untuk mengetahui keberadaan tumbuhan obat yang ada di Desa Bemban, berdasarkan informasi yang sudah diperoleh dari wawancara diatas, maka dilakukan kegiatan pengumpulan data melalui analisis vegetasi. Metode yang digunakan adalah metode garis berpetak dan ditempatkan secara purposive sampling. Pada lokasi penelitian akan dibuat 3 jalur pengamatan dengan panjang jalur 100-300 meter, jumlah petak pengamatan sebanyak 12 petak dan untuk luas tiap petak adalah 0,04 hektar dengan jarak antar petak dalam satu jalurnya yaitu 50 meter. Jadi, luas keseluruhan areal pengamatan adalah 0,48 hektar. Alat dan bahan yang digunakan adalah peta lokasi penelitian, GPS, meteran dan tali, phiband, parang, tally sheet, kuisioner, alat tulis, buku daftar tumbuhan obat, kamera, alkohol 70\%, isolasi, gunting, label, kertas koran.

\section{Analisa Data}

Data yang diperoleh di analisis dengan menggunakan rumus perhitungan, indeks nilai penting (INP), (Budhi dan Ferianita, 2007).

Indeks Nilai Penting (INP) 
Indeks nilai penting digunakan untuk menentukan dominasi suatu jenis terhadap jenis lainnya dalam suatu tegakan.

$$
\mathbf{I N P}=\mathbf{R D i}+\mathbf{R f i}+\mathbf{R c i}
$$

Dimana :

INP = Indeks nilai penting spesies ke-i

$\mathrm{RDi}=$ Kerapatan relatif

Rfi $=$ Frekuensi relatif

Rci $=$ Dominansi relatif

Kerapatan (Density)

Kerapatan adalah jumlah individu di dalam unit area. Kerapatan Relatif (Relatif Density) adalah jumlah individu untuk spesies tertentu (ni) dibagi dengan jumlah total individu untuk seluruh spesies.

$\operatorname{Kerapatan}(\mathrm{Di})=\frac{n i}{A}$

Kerapatan relatif $(\mathrm{RDi})=\frac{n i}{\sum n} \times 100 \%$

Dimana :

$\mathrm{Di}=$ Kerapatan spesies ke- $\mathrm{i}$

$\mathrm{RDi}=$ Kerapatan relatif spesies ke-i

$\mathrm{ni}=$ Jumlah individu spesies ke-i

$\mathrm{A}=$ Luas total sampel area

$\sum \mathrm{n}=$ Jumlah seluruh spesies

Frekuensi

Frekuensi merupakan kemungkinan ditemukannya spesies tertentu di dalam luasan sampel. Frekuensi relatif (Rfi) adalah frekuensi untuk spesies tertentu dibandingkan dengan jumlah frekuensi untuk semua jenis.

Frekuensi (fi) $=\frac{j i}{k}$

Frekuensi Relatif $(\mathrm{Rfi})=\frac{f i}{\sum f} \times 100 \%$

Dimana :

fi $=$ Frekuensi spesies ke- $\mathrm{i}$

Rfi $=$ Frekuensi relatif spesies ke-i

$\mathrm{ji}=$ Jumlah sampel plot dimana spesies ke-

i ditemukan

$\mathrm{k}=$ Jumlah total sampel plot $\sum \mathrm{f}=$ Frekuensi seluruh spesies

Indeks Dominansi $(C)$

Indeks dominansi adalah parameter yang menyatakan tingkat terpusatnya dominansi (penguasaan) spesies dalam suatu komunitas. (Misra, 1973).

Indeks Dominansi $(\mathrm{C})=\sum\left(\frac{n \cdot i}{N}\right)^{2}$

Dimana :

$\mathrm{C}=$ Indeks dominansi

$\mathrm{n} . \mathrm{i}=$ Indeks nilai penting spesies ke-i

$\mathrm{N}=$ Jumlah indeks nilai penting seluruh spesies

Indeks Keanekaragaman Jenis $(H)$

Indeks keanekaragaman jenis digunakan untuk menentukan jenis tegakan hutan. (Odum, 1993).

Indeks Keanekaragaman Jenis $(\mathrm{H})=-\sum\{$ $\left.\left(\frac{n \cdot i}{N}\right) \log \left(\frac{n \cdot i}{N}\right)\right\}$

Dimana :

$\mathrm{H}=$ Indeks keanekaragaman jenis

n. $\mathrm{i}=$ Indeks nilai penting suatu spesies ke- $\mathrm{i}$

$\mathrm{N}=$ Total indeks nilai penting seluruh spesies

Indeks Kekayaan Jenis (R1)

(Ludwig, 1988).

$$
\mathrm{R} 1=\frac{(S-1)}{\log \mathrm{N}}
$$

Dimana :

$\mathrm{RI}=$ Indeks kekayaan jenis

$\mathrm{S}=$ Jumlah jenis yang ditemukan

$\mathrm{N}=$ Jumlah total individu

Indeks Kelimpahan Jenis $(E)$

(Odum, 1993)

$$
\mathrm{E}=\frac{\mathrm{H}}{\log \mathrm{S}}
$$

$\mathrm{E}=$ Indeks kelimpahan jenis

$\mathrm{H}=$ Indeks keanekaragaman jenis

$\mathrm{S}=$ Jumlah seluruh jenis

HASIL DAN PEMBAHASAN 
Hasil penelitian ditemukan 87 jenis tumbuhan obat dari 59 famili. Sebanyak 58 jenis tumbuhan obat dari 34 famili diambil langsung masyarakat di sekitar pekarangan rumah, dan 29 jenis tumbuhan obat dari 25 famili ditemukan dari hasil analisis vegetasi di lapangan. Untuk lebih jelasnya dapat dilihat rekapitulasi data jenis tumbuhan obat pada Tabel 1 dan 2 sebagai berikut :

Tabel 1. Jenis Tumbuhan Obat Yang Ditemukan dan Digunakan oleh Masyarakat Desa Bemban (Medicinal plant species discovered and used by the Bemban Village people)

\begin{tabular}{|c|c|c|c|c|c|}
\hline No & Nama Lokal & Nama Latin & Famili & Habitus & Ket \\
\hline 1 & Asam & Mangifera pajang Koesterm & Anacardiaceae & Pohon & $\sqrt{ }$ \\
\hline 2 & Unjung buah & Phylanthus urinaria Linn & Phyllanthaceae & Herba & - \\
\hline 3 & Ati-ati & Coleus scutellarioides Linn & Lamiaceae & Herba & - \\
\hline 4 & Banglai & Zingiber purpureum Roxb & Zingiberaceae & Herba & - \\
\hline 5 & Bawang merah & Allium cepa $\operatorname{Linn}$ & Liliaceae & Herba & - \\
\hline 6 & Bawang putih & Allium sativum Linn & Liliaceae & Herba & - \\
\hline 7 & Belimbing wuluh & Averrhoa bilimbi L. & Oxalidaceae & Perdu & - \\
\hline 8 & Belian & Eusideroxylon zwageri & Lauraceae & Pohon & $\sqrt{ }$ \\
\hline 9 & Betadin & Jatropha multifida Linn & Euphorbiaceae & Perdu & - \\
\hline 10 & Bintangor & Calophyllum inophyllum & Cluciaceae & Pohon & $\sqrt{ }$ \\
\hline 11 & Buas-buas & Premna cordiflora & Verbenaceae & Perdu & - \\
\hline 12 & Bunga jarum & Ixora stricter Roxb & Rubiaceae & Semak & - \\
\hline 13 & Bunga norjat & Tagetes erecta Linn & Asteraceac & Herba & - \\
\hline 14 & Cangkok manis & Sauropus androgynus Linn.Merr & Euphorbiaceae & Semak & - \\
\hline 15 & Cekur & Kaempferia galanga Linn & Zingiberaceae & Herba & - \\
\hline 16 & Cengkodok & Melastoma malabathricum & Melastomataceae & Perdu & - \\
\hline 17 & Ceplukan & Physallis perwiana Linn & Solanaceae & Herba & - \\
\hline 18 & Daun dewa & Gynura segetum Lour.Merr & Asteraceac & Herba & - \\
\hline 19 & Daun kupu-kupu & Bauhinia sp & Fabaceae & Liana & $\sqrt{ }$ \\
\hline 20 & Daun kaet-kaet & - & - & Liana & - \\
\hline 21 & Daun muje & - & - & Herba & - \\
\hline 22 & Daun sembung & Blumea balsamifera $\mathrm{L}$. & Asteraceae & Herba & - \\
\hline 23 & Daun sop & Apium graveolens Linn & Apiaceae & Herba & - \\
\hline 24 & Daun tumbuh daun & Kalanchoae pinnata & Crassulaceae & Herba & - \\
\hline 25 & Daun tutup bumi & - & - & Herba & - \\
\hline 26 & Durian & Durio zibethinus & Malvaceae & Pohon & $\sqrt{ }$ \\
\hline 27 & Entemu & Curcuma zedoaria Berg.Rosceo & Zingiberaceae & Herba & - \\
\hline 28 & Entemu kuning & Curcuma xanthorrhiza Roxb & Zingiberaceae & Herba & - \\
\hline 29 & Gelinggang & Cassia alata & Fabaceae & Perdu & - \\
\hline 30 & Inai & Lawsonia inermis & Lythraceae & Perdu & - \\
\hline 31 & Jahe & Zingiber officinale Linn & Zingiberaceae & Herba & - \\
\hline 32 & Jambu gendos & Bellucia pentamera & Melastomataceae & Pohon & $\sqrt{ }$ \\
\hline 33 & Jambu tukal & Psidium guajava Linn & Myrtaceae & Pohon & - \\
\hline 34 & Jengkol & Archidendron pauciflorum & Fabaceae & Pohon & - \\
\hline 35 & Jeruju & Acanthus ilicifolius Linn & Acanthaceae & Semak & - \\
\hline 36 & Jintan & Coleus ambanicus Laur & Lamiaceae & Semak & - \\
\hline 37 & Kalimaok & Ageratum conyzoides Linn & Asteraceae & Herba & - \\
\hline 38 & Kayu bengkal & Nuclea maingayi Hook & Rubiaceae & Pohon & $\sqrt{ }$ \\
\hline 39 & Kayu kumpang & Horsfieldia subglobosa & Myristicaceae & Pohon & $\sqrt{ }$ \\
\hline 40 & Kayu unggang & Cratoxylon arborescens & Hypericaceae & Pohon & $\sqrt{ }$ \\
\hline 41 & Keladi & Colocasia gigantea & Araceae & Herba & - \\
\hline 42 & Keladi hutan & Colocasia sp & Araceae & Herba & $\sqrt{ }$ \\
\hline 43 & Keladi tikus & Typhonium flagelliforme & Araceae & Herba & - \\
\hline
\end{tabular}




\begin{tabular}{ll}
44 & Kelapa \\
45 & Kemale ujan \\
46 & Kesum \\
47 & Kumis kucing \\
48 & Kunyit \\
49 & Leban bulan \\
50 & Lengkuas \\
51 & Litu-litu \\
52 & Mahang \\
53 & Mahkota dewa \\
54 & Majau burung \\
55 & Maram \\
56 & Melur \\
57 & Mengkudu \\
58 & Mentawa \\
59 & Nangka belanda \\
60 & Ondie-ondie \\
61 & Pake \\
62 & Paku ceker ayam \\
63 & Paku raja \\
64 & Pandan hutan \\
65 & Pasak bumi \\
66 & Pecah piring \\
67 & Pegage \\
68 & Pelae \\
69 & Pepaya \\
70 & Putri malu \\
71 & Pucuk pulong \\
72 & Putar wali \\
73 & Saoh \\
74 & Serai \\
75 & Sangotipo \\
76 & Simpur \\
77 & Sirih hutan \\
78 & Rumput rembang \\
79 & Tanglong \\
80 & Tajuk langit \\
81 & Tapak kuda \\
82 & Tempuyang \\
83 & Tengkawang \\
84 & Timun tikus \\
85 & Ubi kayu \\
& Tukas \\
\hline 5 \\
\end{tabular}

Cocos nucifera Linn

Drymoglossum piloselloides Linn

Polygonum minus

Orthosiphon aristatus

Curcuma domestica

Vitex pubescens

Alpinia galanga Linn.Willd

Ligodium circinatum

Macaranga triloba

Phaleria macrocarpa Scheff.Boer

Cratoxylon borescens

Elephantopus scaber Linn

Jasminum sambac Ait

Morinda citrifolia Linn

Artocarpus anisophyllus

Annona muricata Linn

Chassalia curviflora

Plumeria rubra Linn

Polypodium selaginella sp

Blechnum orientale $\mathrm{L}$

Pandanus amaryllifolius Roxb

Eurycoma longifolia Jack

Gardenia augusta Merr

Centella asiatica

Alstonia scholaris

Carica papaya Linn

Mimosa pudica Linn

Oldenlandia corymbosa Linn

Tinospora crispa Linn

Achras zapota

Cymbopogon citratus

Zingiber aromaticum

Dillenia excelsa Jack

Piper betle

Scleria laevis Willd

Hibiscus rosa-sinensis

Helminthostachys zeylanica Hook

Bauhinia sp

Zingiber amaricans

Shorea stenoptera Burck

Zehneria indica

Manihot esculenta

Nepenthes bicalcarata
Arecaceae

Polypodiaceae

Polygonaceae

Lamiaceae

Zingiberaceae

Verbenaceae

Zingiberaceae

Schizaceae

Euphorbiaceae

Thymelaeaceae

Hypericaceae

Asteraceae

Oleaceae

Rubiaceae

Moraceae

Annonaceae

Rubiaceae

Apocynaceae

Polypodiaceae

Polypodiaceae

Pandanaccae

Simarubaceae

Rubiaceae

Apiaceae

Apocynaceae

Caricaceae

Fabaceae

Rubiaceae

Menispermaceae

Sapotaceae

Poaceae

Zingiberaceae

Dilleniaceae

Piperaceae

Cyperaceae

Malvaceae

Ophioglossaceae

Fabaceae

Zingiberaceae

Dipterocarpaceae

Cucurbitaceae

Euphorbiaceae

Nepenthaceae

$\begin{array}{ll}\text { Pohon } & - \\ \text { Herba } & - \\ \text { Herba } & - \\ \text { Herba } & - \\ \text { Herba } & - \\ \text { Pohon } & \sqrt{ } \\ \text { Herba } & - \\ \text { Herba } & \sqrt{ } \\ \text { Pohon } & \sqrt{ } \\ \text { Perdu } & - \\ \text { Pohon } & \sqrt{ } \\ \text { Herba } & - \\ \text { Semak } & - \\ \text { Perdu } & - \\ \text { Pohon } & \sqrt{ } \\ \text { Pohon } & - \\ \text { Herba } & \sqrt{ } \\ \text { Perdu } & - \\ \text { Herba } & \sqrt{ } \\ \text { Herba } & \sqrt{ } \\ \text { Perdu } & \sqrt{ } \\ \text { Perdu } & - \\ \text { Semak } & - \\ \text { Herba } & - \\ \text { Pohon } & \sqrt{ } \\ \text { Herba } & - \\ \text { Terna } & - \\ \text { Herba } & - \\ \text { Liana } & \sqrt{ } \\ \text { Pohon } & - \\ \text { Herba } & - \\ \text { Herba } & \sqrt{ } \\ \text { Pohon } & \sqrt{ } \\ \text { Liana } & \sqrt{ } \\ \text { Herba } & \sqrt{ } \\ \text { Semak } & - \\ \text { Terna } & \sqrt{ } \\ \text { Perdu } & \sqrt{ } \\ \text { Pehba } & - \\ & \end{array}$

Keterangan : $(\sqrt{ })$ ditemukan di petak pengamatan/Hutan Lindung Gunung Ambawang ( - ) tidak ditemukan di petak pengamatan

Berdasarkan hasil wawancara dengan masyarakat di Desa Bemban, diperoleh 87 jenis tumbuhan obat yang biasa digunakan oleh masyarakat setempat. Dari 87 jenis tumbuhan obat tersebut, 29 jenis tumbuhan obat diantaranya ditemukan di Hutan Lindung Gunung Ambawang dan 58 jenis tumbuhan obat diambil langsung masyarakat disekitar pekarangan rumah. Dari hasil penelitian menunjukkan bahwa jenis yang dominan pada tingkat 
semai dan tumbuhan bawah, famili dari Schizaceae yaitu Litu-litu (Ligodium circinatum), pada tingkat pancang, famili dari Verbenaceae yaitu Leban bulan (Vitex pubescens), sedangkan pada tingkat tiang, famili dari Euphorbiaceae yaitu Mahang (Macaranga triloba), dan pada tingkat pohon, famili dari Malvaceae yaitu Durian (Durio zibethinus) yang terdapat dalam jumlah besar dan terdapat pada hampir setiap petak pengamatan pada masing-masing jalur dibandingkan dengan jenis tegakan yang lain.

Indeks Nilai Penting (INP)

Sedangkan untuk jenis tumbuhan obat dengan INP terendah atau yang sudah mulai sulit untuk ditemukan pada tingkat semai dan tumbuhan bawah, famili dari Piperaceae yaitu Sirih hutan (Piper betle), pada tingkat pancang, famili dari Moraceae yaitu Mentawa (Artocarpus anisophyllus), pada tingkat tiang, famili dari Lauraceae yaitu Belian (Eusideroxylon zwageri), dan pada tingkat pohon, famili dari Hypericaceae yaitu Majau burung (Cratoxylon borescens).

Indeks Dominansi (C) dan Keanaekaragaman Jenis $(H)$
Nilai indeks dominansi (C) termasuk rendah, karena nilai total indeks dominansi dari hampir semua tingkatan pertumbuhan belum mencapai nilai indeks dominansi tinggi $(\mathrm{C}=1)$. Hal ini menunjukkan bahwa komunitas pada semua jalur penelitian tidak ada yang mendominasi dalam arti semua posisi jenis tegakan tersebut merata dan menunjukkan bahwa pada semua jalur penelitian tidak hanya satu jenis tegakan yang mendominasi tetapi dikuasai atau didominasi oleh beberapa jenis tegakan. Nilai indeks keanekaragaman jenis untuk semua tingkatan pertumbuhan, sedang melimpah karena nilainya lebih dari 1 dan kurang dari $3(1 \geq \mathrm{H} \leq 3)$.

Indeks Kekayaan Jenis (R1) dan Kelimpahan Jenis (E)

Nilai indeks kekayaan jenis (R1) untuk semua tingkatan pertumbuhan tinggi, karena total nilai indeks kekayaan jenis dari semua tingkat pertumbuhan tinggi $(\mathrm{R} 1>5,0)$. Sedangkan untuk nilai indeks kelimpahan jenis (E) tergolong tinggi, karena semua total nilai indeks kelimpahan jenis dari semua tingkat pertumbuhan sudah mencapai nilai yaitu $(E=0,5-1)$. 
Tabel 2. Rekapitulasi Nilai Indeks Dominansi (C), Indeks Keanekaragaman Jenis (H), Indeks Kekayaan Jenis (R1) dan Indeks Kelimpahan Jenis (E), Untuk Semua Tingkat Pertumbuhan Pada Jalur Pengamatan (Recapitulation Values Of The Dominance Index (C), Diversity Index (H), Species Richness Index (R1) and Abundance Index (E) For All Levels Of Growth On The Observation Track)

\begin{tabular}{ccccc}
\hline $\begin{array}{c}\text { Tingkat } \\
\text { Pertumbuhan }\end{array}$ & C & H & R1 & E \\
\hline Semai & 0,4988 & 2,5084 & 39,1225 & 2,8376 \\
Pancang & 0,6758 & 1,3165 & 11,6661 & 2,8474 \\
Tiang & 0,8183 & 1,7953 & 12,8622 & 2,8812 \\
Pohon & 0,5782 & 2,3526 & 31,1198 & 2,7965 \\
\hline
\end{tabular}

\section{Kesimpulan}

1. Berdasarkan hasil penelitian di lapangan, untuk hasil wawancara dengan masyarakat ditemukan secara keseluruhan terdapat 87 jenis tumbuhan obat dari 59 famili. Sebanyak 58 jenis tumbuhan obat dari 34 famili diambil langsung oleh masyarakat di sekitar pekarangan rumah, dan 29 jenis tumbuhan obat dari 25 famili ditemukan dari hasil analisis vegetasi di lapangan.

2. Jenis yang memiliki INP paling besar pada tingkat semai dan tumbuhan bawah yaitu Litu-litu (Ligodium circinatum) dari famili Schizaceae, Pteridophyta, pada tingkat pancang yaitu Leban bulan (Vitex pubescens) dari famili Verbenaceae, sedangkan pada tingkat tiang yaitu Mahang (Macaranga triloba) dari famili Euphorbiaceae, dan pada tingkat pohon yaitu Durian (Durio zibethinus) dari famili Malvaceae, untuk nilai indeks dominansi (C) termasuk rendah, karena nilai total indeks dominansi dari semua tingkat pertumbuhan kurang dari satu, untuk nilai indeks keanekaragaman jenis
(H) untuk tingkat semai dan tumbuhan bawah, pancang, tiang dan pohon sedang melimpah, karena nilai $\mathrm{H}$ lebih dari 1, untuk nilai indeks kekayaan jenis (R1) termasuk tinggi, karena semua total nilai indeks kekayaan jenis dari semua tingkat pertumbuhan lebih dari 5, dan untuk nilai indeks kelimpahan jenis (E) termasuk tinggi, karena semua total nilai indeks kelimpahan jenis dari semua tingkat pertumbuhan lebih dari satu.

\section{Saran}

1. Perlu penelitian lebih lanjut untuk tumbuhan dengan INP rendah di kawasan hutan lindung Gunung Ambawang yang berpotensi sebagai obat dan belum dibudidayakan oleh masyarakat setempat, diantaranya Putar wali, Sirih hutan, Majau burung, Kayu kumpang dan Belian.

\section{DAFTAR PUSTAKA}

Al-Rasyid, H. 1991. Pengembangan Diverifikasi Hasil Hutan Tanaman Obat. Pelestarian Pemanfaatan Tumbuhan Obat dari Hutan Tropis Indonesia. Bogor. 
Budhi, S. 2007. Penuntun Praktikum Ekologi Hutan. Fakultas Kehutanan Universitas Tanjungpura. Pontianak.

Ferianita, F.M. 2007. Metode Sampling Bioekologi. Bumi Aksara. Jakarta.

Heyne, K. 1987. Tumbuhan Berguna Indonesia I-IV. Jakarta : Badan Litbang Kehutanan \& Yayasan Sarana Wana Jaya.

Hidayat, D dan Hardiansyah, G. 2012. Studi Keanekaragaman Jenis Tumbuhan Obat di Kawasan IUPHHK PT. Sari Bumi Kusuma Camp Tontang Kabupaten Sintang. Jurnal Obat Vol. 8 (2) : 61-68.

Indriyanto. 2006. Ekologi Hutan. Bumi Aksara. Jakarta.

Nuryamin, A. 2005. Studi Potensi Tumbuhan Obat Akar Kuning (Arcangelisia flava (L.) Merr.), Pasak Bumi (Eurycoma longifolia Jack.), Seluang Belum (Luvunga eleutherandra Dalz.), dan Ginseng Kalimantan (Psychotria valetonii Hochr.) di Areal Kerja HPH PT. Manimbun Djaja (Djajanti Group) Kalimantan Tengah. Jurnal Obat 13 (2) : 2025.

Suhra, S.F. 2002. Pemanfaatan Tumbuhan Obat oleh Masyarakat Madura (Studi Kasus pada Masyarakat di Desa Nyapar Kecamatan Dasuk Kabupaten Sumenep). [Skripsi] Malang :
Jurusan Pendidikan Biologi UMM.

Wardah, 2009. Potensi Keanekaragaman Tumbuhan Obat Pasca Bersalin di Taman Nasional Gunung Halimun Salak, Kasepuhan Desa Cisungsang, Banten Selatan. Jurnal Bahan Alam Indonesia Vol. 7 (1) : 14122855.

Winarto W. P. 2007. Tanaman Obat Indonesia Untuk Pengobatan Herbal Jilid I. Karyasri Pustaka Herba Indonesia. 